\title{
Expression and Role of Dickkopf-I (Dkkl) in Tumors: From the Cells to the Patients
}

This article was published in the following Dove Press journal: Cancer Management and Research

\author{
Guohua Zhu ${ }^{1,2, *}$ \\ Jukun Song $\mathbb{D}^{2,3, *}$ \\ Weimin $\mathrm{Chen}^{3, *}$ \\ Dongbo Yuan ${ }^{2,3}$ \\ Wei Wang ${ }^{2}$ \\ Xiaoyue Chen ${ }^{3}$ \\ Hen Liu ${ }^{2,4}$ \\ $\mathrm{HaOSu^{2,4 }}$ \\ Jianguo Zhu (iD) ${ }^{1-4}$
}

'Guizhou Medical University, Guiyang, Guizhou Province 550002, People's Republic of China; ${ }^{2}$ Department of Urology, Guizhou Provincial People's Hospital, Guiyang, Guizhou Province 550002, People's Republic of China;

${ }^{3}$ Guizhou University School of Medicine, Guiyang, Guizhou Province 550025, People's Republic of China; ${ }^{4}$ Zunyi Medical University, Zunyi, Guizhou Province 563000, People's Republic of China

*These authors contributed equally to this work
Correspondence: Jianguo Zhu Department of Urology, Guizhou Provincial People's Hospital,, Guiyang, Guizhou Province 550002, People's Republic of China $\mathrm{Tel} / \mathrm{Fax}+86-85 \mathrm{I}-85925503$

Email doctorzhujianguo@163.com

\begin{abstract}
Dickkopf-1 (Dkkl) is a secretory antagonist of the classical Wnt signaling pathway. Many studies have reported that $D k k 1$ is abnormally expressed in tumor cells, and abnormal expression of $D k k l$ can inhibit cell proliferation or induce apoptosis through proapoptotic factors, However, due to the differences in tumor environment and the complex regulatory mechanisms in different tumors, $D k k l$ has different effects on the progression of different tumors. In many tumors, high expression of $D k k 1$ may promote tumor metastasis. However, $D k k 1$, which is highly expressed in other tumors, can inhibit tumor invasion and metastasis. More and more evidence shows that $D k k 1$ plays a complex and different role in tumor occurrence, development and metastasis in different tumor environments and through a variety of complex regulatory mechanisms. Therefore, $D k k 1$ may not only be a useful biomarker of metastasis, but also a target for studying the metabolic mechanism of tumor cells and treating tumors in many tumor types. Therefore, this article reviews the research progress on the expression, mechanism and function of $D k k 1$ in different tumors, and at the same time, based on the public database data, we made a further analysis of the expression of $D k k 1$ in different tumors.
\end{abstract}

Keywords: dickkopf-1, Dkk1, Wnt signaling pathway, tumor mechanism, metastasis, biomarker, in vitro, in vivo

\section{Introduction}

Dickkopf-1(Dkk1), a typical secretory antagonist of Wnt signaling pathway, was discovered in 1998. Dkkl is a secretory glycoprotein with two conserved domains rich in cysteine and a connecting region of 50-55 amino acids. The full length of human Dkkl gene is $1815 \mathrm{~kb}$, which is located on chromosome 10q11.2.26. The $D k k 1$ protein consists of 266 amino acids and its relative molecular weight is about 29 kDa. Dkk2, Dkk3 and Dkk4 have sequence homology in vertebrates, in which $D k k 2$ and $D k k 4$ can inhibit Wnt signal, but the inhibitory effect is weaker than $D k k 1$, and the mechanism of $D k k 3$ is still unclear. ${ }^{1-4}$

Wnt signal pathway includes the classical pathway (Wnt/ $\beta$-catenin) and the non-classical pathway., ${ }^{5,6}$ In the classical pathway, the activity of Wnt is mediated by the close regulation of $\beta$-catenin stability. ${ }^{7}$ Current studies have shown that $D k k 1$ acts in these ways: $D k k 1$ specifically inhibits the typical Wnt signal pathway by competing with the receptor LRP5/6.57-59 for Wnt ligand; the other is that the formation of the complex of $D k k 1$ with $L R P 5 / 6$ and KrementFrizzled leads to the phosphorylation of $\beta$-catenin, which inhibits the downstream regulation of cell cycle, tissue and organ fibrosis and other related target gene expression. ${ }^{8,9}$ 
In the non-classical pathway, the Wnt pathway is activated in two ways, one is the non-canonical Wnt/PCP (planar cell polarity) pathway: Wnt ligand binding to frizzled receptors leads to activation of Dishevelled (Dvl) which recruits DAAM1 (Dishevelled associated activator of morphogenesis 1) enhancing the stimulation of GTPases Rac (Ras-related C3 botulinum toxin substrate) and RHOA (Ras homolog gene family member A) leading to actin cytoskeleton rearrangement. In addition, Dvl activates Rac and finally $J N K$ (c-Jun-N-terminal-kinase) thereby modulating cell migration; ${ }^{10}$ The other is the Wnt/calcium pathway: Wnt ligands bind to frizzled receptors and Ror/Ryk co-receptors, activating Dvl and trimeric G-proteins $(\mathrm{G} \alpha, \beta, \gamma)$. This leads to the generation of IP3 (inositol 1,4,5-triphosphate) and $D A G 2$ (diacylglycerol) through PLC (Phospholipase C) activation. IP3 triggers the release of calcium ions $(\mathrm{Ca} 2+)$ from the endoplasmic reticulum activating calmodulin and subsequently CAMKII (calcium/calmodulin-dependent kinase II), TAK-1 (TGF- $\beta$ activated kinase 1) and $N L K$ (Nemo-like kinase) thereby inhibiting the canonical Wnt pathway. Moreover, calmodulin activation stimulates calcineurin and NFAT (Nuclear Factor of Activated T-cells) involved in adhesion and migration processes. This pathway activates also $P K C$ (Protein Kinase C) and $C d c 42$ (cell division control protein 42 ) rearranging the actin cytoskeleton. ${ }^{11}$

In the Wnt pathway, mutations at key sites, methylation of the promoter and stability of $\beta$-catenin have been shown to be associated with tumor progression and low survival in patients: The progression of chronic phase CML toward blastic crisis phase due to GSK3 $\beta$ mutations and $\beta$-catenin stabilization in GMP cells (granulocyte-macrophage progenitor cells). ${ }^{12}$ And Wnt pathway inhibitor promoters (ie, SFRP,DKK and WIF-1) are hypermethylated in ALL and AML and are associated with low survival in patients. ${ }^{13,14}$ Loss-of-function mutations in APC and RNF43 and gainof-function mutations in $R S P O$ (characterized by gene fusions) and CTNNB1 was reported in the vast majority of colorectal cancers (CRC). ${ }^{15}$

Some studies have proven that high expression of $D k k l$ can occur in a variety of cancer cell lines (such as liver cancer, lung cancer, breast cancer, glioma, and cervical cancer) which induce apoptosis by inhibiting cell proliferation and transformation. ${ }^{16,17}$ Therefore, some researchers believe that $D k k 1$ has the potential to be used as a biological marker for the diagnosis and prognosis of a variety of cancers. ${ }^{18-20}$ But in other tumors, the expression of Dkkl exists as a tumor suppressor. Because of the complex regulation mechanism in different tumors and the influence of different tumor environments, the effect of $D k k l$ on tumor shows two sides.

\section{Expression of Dkkl in Lung Cancer}

Lung cancer is one of the leading causes of cancer death in the world. In recent years, advances in diagnosis and treatment have made remarkable progress in improving the survival of patients with lung cancer, but the survival rate of patients with lung cancer is still low of which NonSmall Cell Lung Cancer (NSCLC) accounts for the vast majority of lung cancer. A study shows that vasculogenic mimicry (VM) may be associated with the maintenance of tumor rich blood supply in highly invasive uveal melanoma, ${ }^{21}$ while epithelial-mesenchymal transformed (EMT) and cancer stem cell-like cell (CSC) have been shown to be associated with $\mathrm{VM}$ in some tumors. ${ }^{22-24}$ Wnt signaling pathway plays an important role in embryonic development and tumorigenesis, so it is closely related to EMT and CSC. ${ }^{25,26}$ The analysis of tumor tissue samples from 205 patients with lung cancer showed that VM could lead to more aggressive cancer and poor prognosis, and it was found that Dkkl was related to histological classification and differentiation in VM. In addition, the overexpression of $D k k 1$ was positively correlated with the existence of VM and the high expression of some VMrelated proteins (MMP2,MMP9 and VE- cadherin). In vitro and in vivo experiments also showed that $D k k 1$ could fully induce EMT and promote the formation of VM. The data showed that CSC phenotype was related to VM and Dkkl overexpression, and in vivo studies showed that lung cancer cells overexpressing Dkkl had more CSC phenotype and more invasiveness than normal lung cancer cells. This study describes the previously unrecognized role of $D k k l$ and confirms the hypothesis that $D k k 1$ promotes VM formation by inducing EMTrelated proteins and developing $\mathrm{CSC}$ properties in NSCLC. ${ }^{27}$

Shen et $\mathrm{al}^{28}$ measured the serum levels of $D k k 1$ autoantibodies in 206 patients with NSCLC and 99 healthy controls by indirect ELISA. The patients were followed up for 3 years to evaluate the correlation between the serological level of antibodies and the overall survival time (OS) and progression-free survival (PFS). The final results showed that the level of autoantibodies in sera of patients with NSCLC was much higher and was closely related to distant metastasis. Cox regression analysis showed that antibodies against Pep B subtype were independent 
prognostic factors of NSCLC. The serum Dkk1 levels of 470 patients with NSCLC (140 bone metastases, 178 extraosseous metastases and 152 complete remission) were quantified and analyzed. The results showed that the serum $D k k 1$ levels of patients with bone metastases were significantly higher than those of the other two groups. After determining the threshold by ROC curve, it was found that the best cutoff value was $311.8 \mathrm{pg} / \mathrm{mL}$, and the serum $D k k 1$ was correlated with the number of bone lesions of bone metastasis, indicating that $D k k 1$ can be used to detect bone metastasis of NSCLC. ${ }^{29}$

\section{Expression of Dkkl in Hepatocellular Carcinoma}

A variety of causes, such as viruses and the environment, can cause Hepatocellular carcinoma (HCC). About 78,200 new confirmed cases are reported each year. ${ }^{30,31}$ The 5year survival rate of $\mathrm{HCC}$ patients varies from stage to stage, ranging from $50 \%$ to $75 \%$ in the early stage, while the 5-year survival rate in HCC patients with distant metastasis is reduced to $3 \%^{32,33}$ In clinical practice, serum Alpha-Fetoprotein $(A F P)$ and ultrasound have been widely used in early screening of liver cancer. ${ }^{34}$ However, when $A F P$ is in the critical range of $20 \mathrm{ng} / \mathrm{mL}$, its sensitivity is reduced to $53 \%$ and specificity is $90 \%$. Therefore, western scholars exclude it from the diagnosis of liver cancer because of its poor sensitivity. ${ }^{35-37}$ By comparing the serum $D k k 1$ levels of 831 test cohort participants and 453 validation cohort participants, and the liver tissue Dkkl mRNA and protein levels of HCC patients and non-cancer patients, Professor Qin Wenxin ${ }^{38}$ found that $D k k 1$ can complement the measurement of $A F P$ in HCC diagnosis, improve the differentiation of AFPnegative $\mathrm{HCC}$ patients, and distinguish HCC from nonmalignant chronic liver disease.

Previous evidence has shown that $D k k 1$ plays a role in promoting angiogenesis during tumorigenesis and inflammation, ${ }^{39}$ Choi et al ${ }^{40}$ stimulated human umbilical vein endothelial cells (HUVEC), with recombinant Dkk1 (rDDK-1) and conditioned medium of 293 cell cultures transfected with $D k k 1$. The expression of angiogenesisrelated factors and EnMT-related markers were detected and formed through test tube. The effects of exogenous Dkkl on angiogenesis and EnMT were evaluated by cell invasion and wound healing tests. The results showed that the increase of EnMT potential of HUVEC stimulated by $D k k l$ was related to the activation of vascular endothelial growth factor receptor 2 (VEGFR2) and its downstream molecules such as Akt and Erk, while the expression of $\beta$ catenin and GSK3 $\beta$ did not change significantly, indicating that $D k k 1$ can induce angiogenesis by regulating VEGFR2 independent of Wnt signal transduction pathway. Surgery (including local hepatectomy and liver transplantation) is still the most effective treatment in the treatment of liver cancer, but due to low diagnostic sensitivity and lack of health awareness, more than $60 \%$ of HCC patients are diagnosed with advanced disease or suffer from multiple diseases and lose the opportunity of operation. ${ }^{41}$ Transcatheter arterial chemoembolization (TACE) once was the first choice for the treatment of inoperable advanced HCC patients. Randomized controlled trials show that TACE can improve the survival rate and quality of life of HCC patients. ${ }^{42}$ However, due to the influence of disease heterogeneity caused by tumor burden, liver function, disease etiology and so on, not all patients who meet the treatment of TACE can benefit from it, ${ }^{43}$ and frequent TACE may aggravate liver injury. Xiaoxia $\mathrm{Wu}^{44}$ retrospectively analyzed the changes of serum $D k k 1$ and circulating tumor cell (CTC) in 155 patients with HCC treated with TACE. It was found that after TACE treatment, the serum Dkkl and CTCs in the reaction group were significantly lower than those before treatment, and the overall survival time, disease-free survival time and 5-year survival rate of patients with positive serum $D k k 1$ and CTC before treatment were significantly lower than those before treatment. It is suggested that the serum Dkkl and CTCs are effective biomarkers to predict the efficacy and longterm prognosis of TACE in patients with HCC. ${ }^{45}$

\section{Expression of Dkkl in Esophageal}

\section{Carcinoma}

Esophageal cancer (EC) is the sixth deadliest cancer disease in the world, and its incidence is increasing year by year. The main pathological type of cancer in Asian and African patients is esophageal squamous cell carcinoma (ESCC), while in European patients, esophageal adenocarcinoma (EAC) is more common. ${ }^{46,47}$ Although great progress has been made in the treatment of EC, compared with its survival rate of only $14 \%,{ }^{48}$ it is still worthy of further study.

By using RT-PCR and Western blot to detect the expression of Dkkl in EC tissues, paired normal esophageal tissues and EC tumor cell lines, it was found that the expression of $D k k 1$ gene was up-regulated at both mRNA 
and protein levels in esophageal cancer tissues. At the same time, $D k k 1$ gene was expressed to varying degrees in all four esophageal cancer cell lines analyzed. However, after the construction of EC9706 cell lines overexpressing $D k k 1$, it was found that the proliferation rate of overexpressed EC9706 cells increased. The proportion of S phase and $\mathrm{G} 2 / \mathrm{M}$ phase increased, while the proportion of G0/G1 decreased, and the overexpression of $D k k 1$ led to the enhancement of invasive ability of EC9706 cells. The results suggest that $D k k 1$ may be a key regulator in the occurrence and development of carcinoma. ${ }^{49}$ By comparing the serum $D k k 1$ levels of 90 ESCC patients and 85 healthy patients by ELISA, it was found that the $D k k 1$ level of ESCC patients was much higher than that of the healthy control group; the sensitivity and specificity for the determination of serum $D k k 1$, were $70 \%$ and $80 \%$ respectively, and the serum Dkkl level of ESCC patients increased before operation, which means that $D k k 1$ may be a useful marker for diagnosing and judging the treatment and prognosis of ESCC patients. ${ }^{50}$ The expression of $D k k 1$ protein in resected specimens of ESCC patients was compared with various clinicopathological parameters and prognosis (the relationship between disease-free survival (DFS)) showed that the DFS of patients with Dkk1-positive tumors was worse than that of ESCC-negative patients (5-year DFS; $1.5 \%$ vs $53.6 \%$ DFS; $1.5 \%$ 0.0062), indicating that $D k k l$ can be used as a new predictor of poor prognosis in patients with ESCC after radical resection. ${ }^{51}$

\section{Expression of Dkkl in Gastric Cancer}

Gastric cancer is the second largest cause of cancer-related death in the world. ${ }^{52}$ Although the development of surgical techniques and targeted therapy has increased the 5-year survival rate of early gastric cancer (EGC) to more than $90 \%,{ }^{53}$ the survival rate of advanced gastric cancer (AGC) is still about $40 \% .{ }^{54}$

A study compared the serum Dkkl of 153 patients with gastric cancer and 173 healthy controls, and the expression of $D k k 1$ in 144 cancer samples of 153 patients and 265 consecutive gastric cancer specimens showed that the serum Dkkl concentration of patients with gastric cancer was significantly higher than that of healthy controls, the critical value was $31.9150 \mathrm{pg} / \mathrm{mL}$, and the sensitivity and specificity for the diagnosis of gastric cancer were $87.6 \%$ and $87.9 \%$, respectively. The survival rate of gastric cancer patients with serum Dkk1 level $\geq 60.0 \mathrm{pg} / \mathrm{mL}$ was significantly lower than that of gastric cancer patients with lower serum $D k k 1 .{ }^{55}$ But what is the expression of Dkkl in patients with gastric cancer and its clinical significance? Zhuang et $\mathrm{al}^{56}$ detected the expression of serum $\mathrm{Dkkl}$ protein in 90 cases of gastric cancer, 50 cases of gastric benign disease and 40 healthy persons by ELISA, and the dynamic changes of serum $D k k 1$ protein in gastric cancer patients undergoing radical operation for 1 month. It was found that the expression of serum $D k k 1$ protein in the gastric cancer group was significantly higher than that in the gastric benign group and the healthy control group. The serum Dkkl level in patients with TNM stage III and IV was significantly higher than that in patients with TNM stage I and II. The level of serum Dkkl was related to microvascular infiltration, degree of differentiation, and depth of invasion. The level of serum Dkkl decreased significantly after radical operation. The results suggest that $D k k l$ detection can be used as a reference index for monitoring the progression and biological behavior of gastric cancer. The results of another meta-analysis also supported this result, and this meta-analysis also found that the overexpression of $D k k l$ was not only associated with vascular and lymphatic invasion, but also with distant metastasis and overall survival of patients with gastric cancer. ${ }^{57}$ In the process of embryonic development and homeostasis of human tissue, Wnt signal cascade regulates cell proliferation, cell polarity, and cell development. ${ }^{7}$ Solid tumors often show an imbalance in the Wnt signal pathway, which is related to the enhancement of malignant potential. ${ }^{58} \mathrm{Dkkl}$ is an antagonist of $\mathrm{Wnt} / \beta$-catenin pathway. After examining the relationship between the coexpression of $D k k 1$ and $\beta$-catenin in gastric cancer and clinical prognosis, it was found that the co-expression of $D k k 1$ and $\beta$-catenin was significantly correlated with high $\mathrm{N}$ stage (N2 and N3). The overall survival (OS) and DFS of patients with high expression of Dkkl were poor. Multivariate analysis showed that high expression of $D k k 1$ alone or high expression of Dkkl with $\beta$-catenin positive were independent prognostic factors for tumor recurrence and overall survival, indicating that high expression of $D k k l$ was an important prognostic factor for tumor recurrence and survival in resected AGC patients, regardless of the positivity of $\beta$-catenin. ${ }^{59}$ The continuous activation of Wnt signaling pathway to maintain the self-renewal and tumorigenicity of gastric cancer stem cell (CSC) is considered to be a target for the treatment of gastric cancer. $\mathrm{CD}_{4} 4^{+}$cells were isolated from primary gastric cancer cells and gastric cancer cell lines by fluorescence activated cell sorting. The expression of adenovirus receptor in $\mathrm{CD} 44^{+}$cells and $\mathrm{CD} 44^{-}$cells was 
detected. Dkk1, a Wnt antagonist, was transfected into CD44Dkk1 cells by Ad5/35 (Ad5/35-Dkk1). After Dkk1 was introduced into $\mathrm{CD} 44^{+}$cells, it effectively inhibited the endogenous $W n t / \beta$-catenin signal transduction and reduced the tumorigenicity of $\mathrm{CD}_{4} 4^{+}$cells in vivo, which verified the effectiveness of gene therapy targeting Wnt/ $\beta$ catenin signal pathway in CSC cells. ${ }^{60}$

\section{Expression of Dkkl in Colorectal Cancer} Colorectal cancer (CRC) is a common malignant tumor of the digestive system ${ }^{61}$ and the fifth leading cause of cancer-related deaths in the Chinese population. ${ }^{62}$ It is closely related to the abnormal activation of $\mathrm{Wnt} / \beta$-catenin signal pathway. ${ }^{63,64}$ In recent years, the incidence of CRC has gradually increased, and tumor metastasis is the main cause of death in patients with $\mathrm{CRC}^{65}$ In metastatic patients, the 5-year survival rate was only about $10 \%$ $\sim 15 \%{ }^{66}$

In an earlier study, some scholars found that $D k k l$ was methylated in CRC cells, and when the expression of $D k k 1$ was restored, there was a decrease in cell colony density and tumor growth inhibition in nude mice. ${ }^{67}$ A large cohort study showed that Dkkl was methylated in $95 \%$ of CRC patients, and its methylation level was closely related to tumor microvessel density. ${ }^{68}$ Immunohistochemistry showed that the expression of $D k k 1$ was down-regulated in colorectal adenoma-carcinoma sequence, and the expression of $D k k 1$ was related to the decrease of microvessel density and the expression of vascular endothelial growth factor $(V E G F)$. At the same time, in vitro culture showed that HCT116 with overexpression of $D k k 1$ inhibited the formation of the tubular structure of human umbilical vein endothelial cells and down-regulated the expression of $V E G F$, and the tumor size, microvessel density and $V E G F$ expression of CRC cells with high expression of $D k k 1$ decreased. ${ }^{69}$ Because the low expression of $D k k 1$ indicates the abnormal activation of the Wnt pathway and is related to the poor prognosis of patients with $\mathrm{CRC}$, it is suggested that we can increase the expression of $D k k 1$ by reducing the factors that inhibit the expression of Dkkl (such as reducing the level of methylation or inhibiting the expression of CSN5) to produce anti-tumor effect. Therefore, the detection of the decrease of $D k k l$ expression can be used as a warning of tumor progression in patients with $\mathrm{CRC}$ and provide an idea for the treatment of tumors. COP9 signalosome (CSN) is a highly conserved polyprotein complex in eukaryotes, which plays an important role in the regulation of the cell cycle, DNA damage response, and apoptosis. Microarray analysis of CRC cell lines showed that the expression of $D k k 1$ and the level of $D k k 1$ protein depended on the increase of $D k k 1$ secretion after CSN5 gene knockout, which affected the Wnt signal transduction of SW480 cells. It is suggested that CSN5 may actively drive abnormal Wnt signals by inhibiting Wnt antagonist $D k k 1$, thus promoting the development of colorectal cancer. ${ }^{70}$ Therefore, understanding the molecular link between CSN5 and Wnt signals may help to design and develop new targets for the treatment of colorectal cancer. MicroRNA (miRNA or miRs) has been proven to be an important post-transcriptional regulator in tumorigenesis. At present, as the focus of tumor mechanism research, through the in vitro study of SW-480 and HCT-116 CRC cell lines, Wang et $\mathrm{al}^{71}$ found that miR-410 was up-regulated in CRC cell lines, and proved that $D k k 1$ is the direct target of miR-410. Knocking down miR-410 can promote the expression of $D k k 1$, inhibit the proliferation, migration and invasion of CRC cells, and induce apoptosis, while the overexpression of miR-410 shows the contrary. Another study also found that the expression level of the long noncoding Long-stranded non-coding RNA (lncRNA) HOXA transcript at the distal tip (HotTip) at the end of CRC cells was significantly higher than that in corresponding adjacent normal tissues, and the expression level of HotTip was higher in patients with larger tumor size, pathological stage or distant metastasis. Silencing the expression of HotTip can inhibit the migration and invasion of colorectal cancer cells. Mechanism studies have shown that HotTip regulates the metastasis of colorectal cancer cells by down-regulating the expression of tumor suppressor gene Dkk1. Therefore, ${ }^{72}$ the potential of miRNA and lncRNA as tumor candidate markers in the diagnosis and treatment of CRC is still worthy of further study.

\section{Expression of Dkkl in Pancreatic Cancer} Pancreatic cancer (PC) ranks fourth in cancer mortality in the United States. ${ }^{73}$ From a pathological point of view, pancreatic duct adenocarcinoma (PDAC) accounts for about $90 \%$ of the pathological classification of $\mathrm{PC}^{74}$ Compared with other cancers of the digestive system, PC has a poor prognosis, with a 5-year survival rate of only $5 \%$ and a median survival time of less than 6 months. ${ }^{75}$ Although surgical treatment is a feasible treatment, $80 \%$ of patients are in advanced stage or with metastasis at the time of diagnosis. ${ }^{76}$ 
A study from Japan observed that there was a significant up-regulation of Dkkl in PC cell line. After comparing the expression of $D k k l$ protein and mRNA in PC tumor tissue and normal pancreatic tissue, the high expression of $D k k l$ in tumor tissue was proved again. Further in vitro experiment found that the invasiveness of PC tumor cells with $D k k l$ knockout was significantly decreased. ${ }^{77}$ In terms of the mechanism of $D k k 1$ regulating PC, gene chip analysis showed that $D k k l$ was an abnormal gene associated with GATA6 gene knockout. Immunoprecipitation and electrophoretic mobility shift analysis confirmed that GATA6 directly bound to the $D k k 1$ promoter. In the case of low GATA6 knock down, it was found that the mRNA expression of $D k k 1$ and the secretion of $D k k 1$ protein increased. Therefore, it has been proven that GATA6 negatively regulates $D k k 1$ transcription by directly binding to the GATA motif in the $D k k 1$ promoter region. ${ }^{78}$ In order to explore the relationship between $D k k l$ and the prognosis of patients with PC, Han et $\mathrm{al}^{79}$ followed up 140 patients with pancreatic adenocarcinoma and 92 patients without PC for 2 years, including serum $D k k 1$ and CA19-9 levels and tumor progression. This study found that serum $D k k l$ and CA19-9 were increased in patients with advanced PC and chronic pancreatitis, but $D k k l$ was more effective in distinguishing PC from chronic pancreatitis than CA19-9, and the survival rate of patients with high expression of $D k k l$ was significantly lower than that of patients with low expression of Dkkl. PCR detection of PDAC and paired normal tissues showed that the expression of $D k k l$ was increased in PDAC tissues, which was confirmed by independent microarray analysis. Kaplan-Meier analysis of $D k k 1$ expression and patient clinical data showed that OS and relapse-free survival (RFS) decreased in patients with high $D k k 1$ expression, and the expression of $D k k 1$ was significantly correlated with $\mathrm{T}$ stage and lymph node metastasis. Univariate and multivariate Cox regression analysis confirmed that $D k k 1$ and lymph node metastasis were independent predictors of OS in patients with PDAC. ${ }^{80}$ Based on the bioinformatics analysis of PDACrelated data sets in the GEO database, it was found that $D k k 1$ and $H M G A 2$ are considered as hub genes with high connectivity, so $D k k 1$ and HMGA2 may become therapeutic targets and prognostic markers of PDAC. ${ }^{81}$ In recent years, more and more attention has been paid to the role of lncRNA in PC. ${ }^{82}$ In order to understand the expression and role of LINC01133 in PC, the relationship between LINC01133 and Dkk1 promoter methylation was founded. After further detecting the expression of genes related to the Wnt signal pathway such as LINC01133 and Dkkl, and using EDU staining, scratch method and Transwell method to detect their effects on tumor cells, it was found that LINC01133 can down-regulate the expression of $D k k 1$ to inhibit the Wnt signal pathway, thus promoting the growth and metastasis of pancreatic cancer. ${ }^{83}$ In the exosome study of PDAC, it was found that the new receptor cytoskeleton-associated protein 4 (CKAP4) of Dkkl could be secreted through the small extracellular vesicle (SEV) of PDAC cells, and showed the characteristics of exosome. Histological and in vitro tumor detection showed that the level of CKAP4 in serum of PDAC patients was higher than that of normal patients, and CKAP4 monoclonal antibody could inhibit $D k k 1$ and $C K A P 4$, and finally inhibit the proliferation and migration of PDAC cells. ${ }^{84}$

\section{Expression of Dkkl in Cervical Cancer}

Cervical cancer (CC) ranks fourth in tumor-related mortality among women. ${ }^{85}$ The transformation from normal cervical epithelium to intraepithelial neoplasia (CIN) and finally to invasive cervical cancer is the most important pathological feature of $\mathrm{CC} .{ }^{86}$ Among the three histological types of adenocarcinoma, squamous cell carcinoma and adenosquamous carcinoma, squamous cell carcinoma is the most common, while human papillomavirus (HPV) is considered to be an independent risk factor in the occurrence of $\mathrm{CC} .^{87,88}$ Corresponding vaccines have been developed for clinical prevention. And more and more studies have also pointed out that the carcinogenic effect of cervical cancer is designed to change a variety of genes. $^{89}$

Some studies have found that the transcription of Dkk1 in $\mathrm{CC}$ is inhibited in epigenetics, while further studies have found that there is a high level of methylation of Dkk1 promoter CpG in CC cell lines, and histone deacetylation is the main epigenetic change, so cell line-dependent and differentiated epigenetic mechanisms may be used to silence Dkkl in CC cells. ${ }^{90}$ By comparing the serum $D k k 1$ and clinical information of patients with cervical cancer, it was found that the level of serum $D k k l$ in patients with cervical cancer was higher than that in healthy subjects, and it was related to the histological type and lymphatic metastasis of CC, so it may be helpful for the diagnosis of $\mathrm{CC} .{ }^{91}$ After simultaneously detecting the serum Dkkl of normal subjects, CIN patients and CC patients and following up their subsequent disease development data, it was found that the serum $D k k l$ level of CC patients was higher than that of normal subjects and CIN 
patients, and the expression of $D k k 1$ was related to lymphatic metastasis and tumor diameter of cervical cancer, and related to the prognosis of cervical cancer patients. It can be used for the detection and diagnosis of $\mathrm{CC}$, and for the prognosis evaluation of CC patients ${ }^{92}$ In view of the important role of lncRNA in the pathological process of cancer, some scholars have studied the role of lncRNA in $\mathrm{CC}$ and found that the promoting effect of $S N H G 7$ on the development of $\mathrm{CC}$ depends on the activation of Wnt pathway mediated by $D k k 1$, while the binding of EZH2 and $D k k 1$ promoter and the share of $H 3 K 27 m e 3$ in $D k k 1$ promoter are decreased after $S N H G 7$ silencing. It has been proven that $S N H G 7$ silences $D k k 1$ through Wnt/ $\beta$-catenin signal transduction pathway to aggravate the malignant degree of $\mathrm{CC} .{ }^{93}$

\section{Expression of Dkkl in Ovarian Cancer}

Although the 5-year survival rate of patients with ovarian cancer has been stable for the past 20 years, it is still at a low level $(30 \% \sim 40 \%)$, making it the deadliest tumor in gynecological tumors. ${ }^{85,94-96}$ Because its early clinical symptoms are not obvious, nearly $2 / 3$ of the patients are in the late stage at the time of diagnosis. ${ }^{97}$ Most $(80 \%)$ of the patients who died had epithelial ovarian cancer (EOC). ${ }^{98}$

By using cDNA microarray to analyze the gene expression profile of metastatic EOC cells, it was found that $D k k 1$ was significantly down-regulated in metastatic tumors. $^{99}$ Through the study of the progress of EOC cells, it was found that STAT3 was overactivated in ovarian cancer, and the expression of $D k k 1$ increased significantly after reducing the expression of STAT3. Further studies found that STAT3 signal regulated tumor progression through miR-92a/ $\beta$-1 and connected with Wnt/Dkkl-catenin signal, thus finding the metabolic pathway of tumor. ${ }^{100}$ The member of 10-11 translocation (TET) family (TET13 ) is the key molecule of DNA demethylation, ${ }^{101,102}$ and its expression is down-regulated in many cancers. ${ }^{103,104}$ In the analysis of EOC, it was found that the expression of TET1 was negatively correlated with the clinical stage of ovarian cancer. Overexpression could inhibit the colony formation, invasion, metastasis and epithelial-mesenchymal transformation of ovarian cancer cells. In terms of mechanism, it was found to be by TET1 through demethylation of Wnt/ $\beta$-catenin signal pathway antagonist $D k k 1$. Therefore, TET1 plays an important anti-tumor role in ovarian cancer by activating $\mathrm{Wnt} / \beta$-catenin signal inhibitor Dkk1. ${ }^{105}$ Cordycepin (3-deoxyadenosineis) the main bioactive component of Cordyceps militaris, which has been reported to inhibit cell proliferation. ${ }^{106-108}$ After further study on ovarian cancer, it was found that cordycepin kit-8 reagent based on cell count decreased the viability of ovarian cancer cells, Western blotting showed that cordycepin could increase the $D k k 1$ and inhibit $\beta$ catenin signal transduction. Overexpression of $D k k 1$ down-regulated the expression of $c-M y c$ and cyclin D1, while silence down-regulated the expression of $\operatorname{Atg} 8$, beclin, and $L C 3$, the results showed that cordycepin might inhibit the growth of ovarian cancer cells through synergistic autophagy and $D k k 1 / \beta$-catenin signal transduction. ${ }^{109}$ After the preparation of monoclonal antibody against $D k k 1$ (DKN-01), the effect of $D k k 1$ on tumor cell phenotype and tumor load was studied in vivo and in vitro. It was found that overexpression of DKN-01 had no significant effect on tumor cell phenotype and tumor load, but overexpression of $D k k 1$ reduced the infiltration of $\mathrm{CD}_{4} 5^{+}$leukocytes into the peritoneum and omentum, reduced natural killer (NK) and CD8T cells, and decreased the expression of interferon- $\gamma(I F N-\gamma)$ on activated CD8T cells. Therefore, these results may indicate that the overexpression of $D k k l$ provides a microenvironment to promote tumor by inhibiting the anti-tumor immune population, so the inhibition of $D k k 1$ may play the best role in combined immunoregulatory therapy. ${ }^{110}$

\section{Expression of Dkkl in Breast Cancer}

Although today, with the rapid development of diagnosis and treatment technology, the prognosis of breast cancer patients is still poor. ${ }^{111,112}$ Tumor metastasis is one of the main causes of death in patients with breast cancer, ${ }^{113}$ so the research based on the mechanism of breast cancer progression and metastasis has become a hot topic.

Compared with normal subjects, the level of serum $D k k 1$ in breast cancer patients was higher, and the level of $D k k 1$ in patients with bone metastasis was higher than that in patients without bone metastasis. ${ }^{114}$ The high expression of $D k k 1$ in triple negative breast cancer patients was regulated with poor prognostic. ${ }^{115} D k k 1$ is associated with the progression of osteolytic bone metastasis by damaging the activity of osteoblasts. ${ }^{116}$ P38 mitogen-activated protein kinase (MAPK) regulates intracellular responses related to cell cycle, apoptosis and tumorigenesis. Inhibition of $P 38$ in breast cancer cell lines can effectively inhibit the expression of $D k k 1$ in breast cancer cells, whereas activation of $P 38$ can up-regulate $D k k 1$, suggesting that $p 38$ may play a role in regulating $D k k 1$ 
in osteolytic tumors. ${ }^{117}$ Previous studies have shown that zoledronic acid and Atto vastatin can block mevalonate pathway to inhibit high expression of Dkkl in hormone receptor negative breast cancer. ${ }^{118}$ But its dosage far exceeds the level of clinical safe use. A new study shows that zoledronic acid combined with low concentrations of statins can increase the inhibitory efficiency of human osteoblast tumor cells by $75 \%$. When low concentrations of statins and zoledronic acid are used at low concentrations, the metastatic rate of $D k k 1$-mediated breast cancer bone metastatic cells can be reversed by at least $50 \%$. Intratumoral injection of Atto vastatin and zoledronic acid can reduce serum $D k k 1$ levels by $25 \% .{ }^{119}$ In the study of mesenchymal stem cell (MSC), it was found that MSCs from the rib perichondrium (PMSCs)-conditioned medium could significantly inhibit the growth, migration and invasion of breast cancer cells, and downregulate the expression of $\mathrm{Wnt} / \beta$-catenin pathway and its target genes, while neutralizing D $k k 1$ in PMSC-conditioned medium could significantly reduce its inhibitory effect on tumor cells. In vivo, PMSCs can inhibit the growth of breast cancer and prolong the survival time of tumor-bearing rats, suggesting that $D k k l$ secreted by PMSC plays an important role in inhibiting the growth of breast cancer cells through Wnt/ $\beta$-catenin pathway. ${ }^{120}$ By comparing the serum $D k k 1$ and $C A 15-3$ between breast cancer patients and healthy subjects, it was found that in the early stage of breast cancer, the sensitivity and specificity of $D k k 1$ were higher than that of $C A 15-3$, while the expression of Dkk1 in HER-2-, ER-, and PR-positive patients was lower than that in HER-2-, ER- and PRnegative patients. ${ }^{121}$ After comparing the serum Dkkl of 89 breast cancer patients and 86 healthy women, and comparing the $D k k 1$ and $\beta$-catenin in adjacent non-neoplastic breast tissues, primary breast tumors, lymph node metastasis and bone metastasis tissues, it was found that the serum $D k k 1$ in breast cancer patients were significantly higher than those in normal subjects, but the increase was more significant in patients with bone metastasis. The expression of $D k k 1$ in lymphoid nodule metastatic tissue and bone metastatic tissue was lower than that in primary tumor tissue and non-neoplastic breast tissue. ${ }^{122}$ Through identification, it was found that a small molecular chemical dorsomorphin could reduce the mRNA and protein levels of $D k k 1$ in breast cancer cell lines by $70 \%$ and $90 \%$, respectively, suggesting that dorsomorphin may be a therapeutic drug for breast cancer. ${ }^{123}$

\section{Expression of Dkkl in Bladder Urothelial Cancer}

Research data from the United States show that bladder urothelial cancer (BUC) accounts for about 7\% of new tumors and $4 \%$ of all cancer deaths. ${ }^{32}$ At the same time, it is also one of the most common urogenital cancers in the People's Republic of China. ${ }^{124}$ BUC is divided into muscle-infiltrating bladder cancer (MIBC) and non-muscleinfiltrating bladder cancer (NMIBC). The incidence of MIBC is high and easily recurs, while NMIBC tends to relapse within 2 years. ${ }^{125,126}$

Through the preoperative detection of serum $D k k 1$ in patients with bladder cancer, it was found that the increase of preoperative $D k k 1$ was closely related to tumor stage, grade and histological grade. ${ }^{127}$ The serum samples of 94 patients with bladder cancer and 60 healthy subjects from the People's Republic of China showed that the serum Dkkl in patients with bladder cancer was significantly higher than that in healthy subjects, and the serum $D k k 1$ was closely related to lymph node metastasis, distant metastasis and TNM staging. The higher the serum Dkkl the lower the survival rate of bladder cancer patients. Multivariate analysis showed that serum $D k k 1$ was an independent prognostic factor for OS of bladder cancer. ${ }^{128}$ Gao et al ${ }^{129}$ demonstrated that up-regulation of $m i R-543-3 p$ in bladder cancer can activate $\mathrm{Wnt} / \beta$-catenin signal by directly targeting $D k k l$, while the expression of $m i R-543-3 p$ is up-regulated in bladder cancer tissues and cells, and is positively correlated with high-grade bladder cancer, suggesting a potential tumor intervention target.

\section{Discussion}

Based on the above studies, most of the human samples were studied in vivo and in vitro. Most studies have pointed out that $D k k 1$ promotes the metastasis of various types of cancer, and is related to the late stage, metastasis and low short survival time of the tumor, and its diagnostic sensitivity is comparable to that of existing biomarkers, even beyond them. ${ }^{38,79}$ But interestingly, in some tumors, $D k k l$ showed tumor inhibitory effect in tumors. ${ }^{61-72}$

Specifically, through the above research, we can find that $D k k 1$ has been shown to promote tumor metastasis in the following tumors: NSCLC, HCC, EC, GC, PC, CC, Breast cancer, and BUC. But In CRC and ovarian cancer, $D k k 1$ has been shown to play an inhibitory role in tumors. 
According to the results of the above literature, we can observe that the high expression of $D k k 1$ can significantly decrease the invasion and metastasis ability of CRC and EOC cells in vitro and in vivo. By comparing the serum samples of tumor patients and normal subjects, we also confirmed the protective effect of high expression of $D k k 1$ on CRC patients. However, high expression of $D k k 1$ was shown in other tumors to promote tumor progression. (Figure 1).

In terms of the mechanism of $D k k 1$ in tumor, according to the correlation between $D k k 1$ and tumor metastasis in vivo and in vitro, the mechanism of action, and the survival time of patients, we have made a summary of the above-mentioned literature, showing the mechanism of promoting tumor is mainly concentrated in the following aspects: 1) promoting tumor angiogenesis ${ }^{27,40,69}$ 2) methylated Dkk1 promoter ${ }^{; 67,68,81}$ 3) STAT3 regulates tumor progression through the interaction between miR92a/ $\beta-1$ pathway and $\mathrm{Wnt} / D k k 1$-catenin signal $^{; 00}$ 4) Synergistic autophagy and $D k k 1 / \beta$-catenin signal transduction regulate tumor progression; and 5) change tumor immune microenvironment. However, in CRC, in vivo experiments showed that overexpression of $D k k l$ caused down-regulation of $V E G F$ expression. Tumor formation experiments in vitro showed that the tumor size, microvessel density and $V E G F$ expression of CRC cells with high expression of $D k k 1$ decreased, and that $C S N 5, m i R$ 410 and HotTip could promote the progress of CRC by inhibiting the expression of $D k k 1 .^{70-72}$ And in EOC, TET1

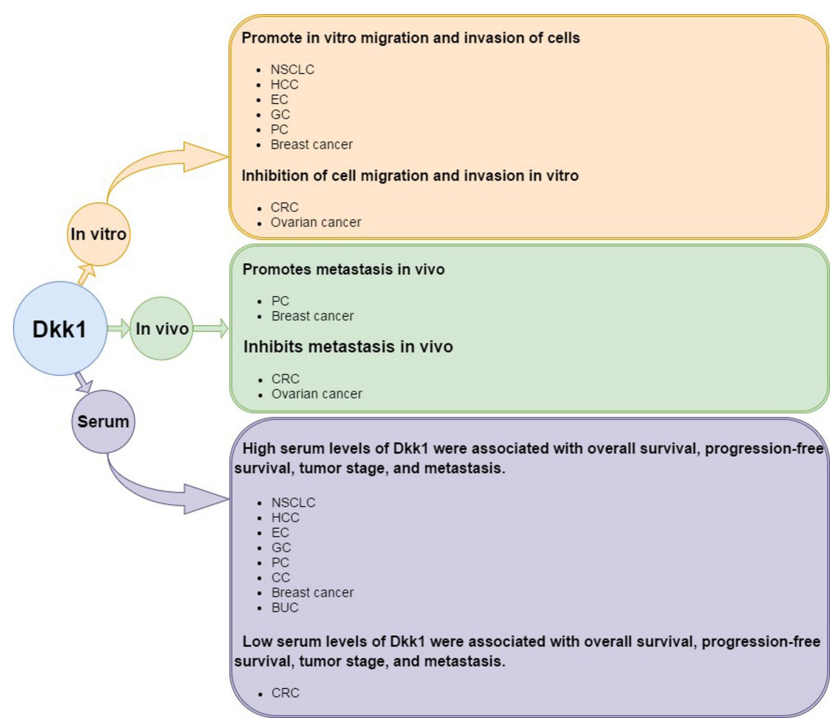

Figure I Summary of the research findings on the role of $D k k l$ in cancers from in vitro and in vivo experiments as well as from studies using serum from human patients. plays a tumor suppressive role in ovarian cancer by activating $D k k 1$ through demethylation. (Table 1)

Current studies have shown that Dkkl regulates tumor progression by inhibiting the downstream regulation of cell cycle, tissue and organ fibrosis and the expression of other related target genes. By downloading the oncology data of TCGA database and the expression data of normal tissue in GETx database, and used $\mathrm{R}$ to analyze the difference of Dkk1 in normal tissue and tumor tissue of different organs, it is found that: the expression of $D k k 1$ in ACC, CHOL, COAD, ESCA, GBM, HNSC, LGG, LIHC, LUAD, LUSC, PAAD, READ, STAD, TGCT, UCEC, and UCS was significantly higher than that in normal tissues, but in BLCA, KICH, PRAD, SKCM, and OV, the expression of Dkkl in tumors was significantly lower than that in normal tissues (Figure 2).

$D k k 1$ plays a role in regulating tumor progression because of its inhibition of classical Wnt pathway in tumors. ${ }^{8,9}$ Therefore, Dkk1 is defined by most studies as a biological marker with the potential to evaluate tumor diagnosis and prognosis. ${ }^{18-20}$ In most tumors, Dkk1 promotes tumor growth and metastasis by promoting angiogenesis and regulating immune microenvironment. However, in other tumor studies, it has been found that $D k k 1$ can inhibit the biological effect of tumor. Some scholars have put forward the following conjectures about the different biological effects of $D k k 1$ in tumors: 1) according to the transduction mode of Wnt signal in cancer cells, inhibiting $\beta$-catenin dependent Wnt signal does not necessarily inhibit tumor; 2) the characterization of $D k k 1$ as a $\beta$-catenindependent Wnt signal inhibitor in cancer cells is too simplistic, and it is important to consider other potential regulatory results of $D k k l$; and 3) in some tumors, the classical Wnt signal pathway is structurally activated downstream of $D k k 1$. In this case, it can be assumed that Dkkl cannot inhibit the transduction of the classical Wnt signal pathway, thus eliminating its potential antitumor activity. ${ }^{130}$

In recent years, Dkkl antibodies have been tried in tumor therapy, but because Wnt signaling is extremely complex, and the role of $D k k 1$ in promoting tumor growth and metastasis in cancer and immune cells in regulating this and other signaling pathways has not been fully elucidated. The close relationship between the expression level of $D k k 1$ in serum of clinical tumor patients and prognosis makes $D k k 1$ an attractive target for tumor 


\begin{tabular}{|c|c|c|c|c|}
\hline 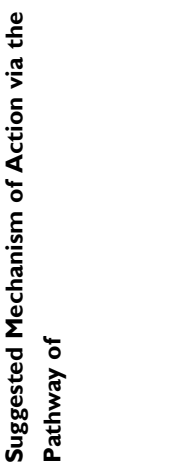 & 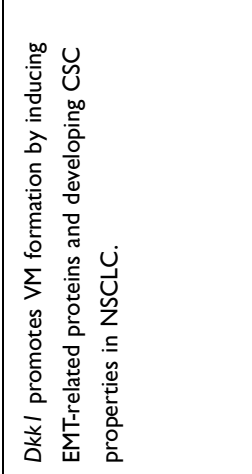 & 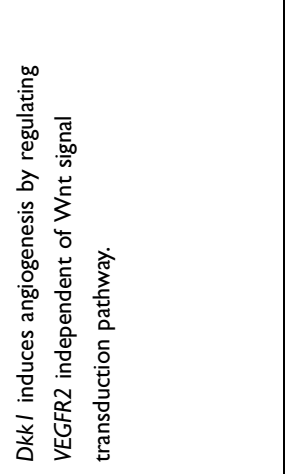 & $\stackrel{\S}{z}$ & 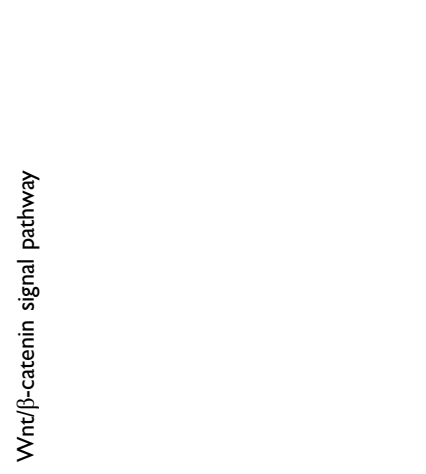 \\
\hline 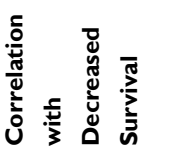 & 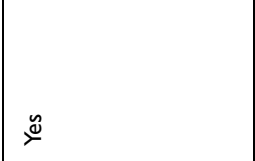 & $\stackrel{\check{g}}{\widetilde{\nu}}$ & $\stackrel{\tilde{s}}{\approx}$ & $\stackrel{\check{\Xi}}{\check{\nu}}$ \\
\hline 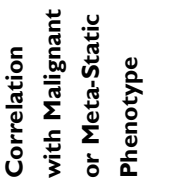 & $\stackrel{\check{g}}{\nearrow}$ & 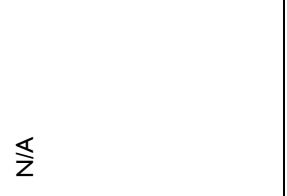 & $\stackrel{y}{\check{\nu}}$ & $\stackrel{\check{\Xi}}{\check{\nu}}$ \\
\hline 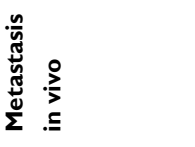 & $\stackrel{\check{\Perp}}{\check{\nu}}$ & 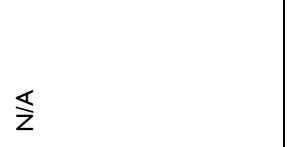 & $\widehat{\Sigma}$ & 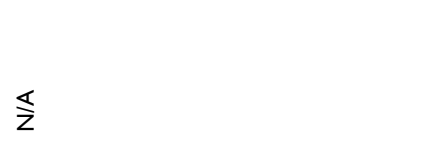 \\
\hline 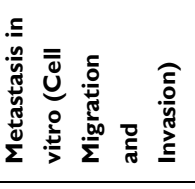 & $\underbrace{y}$ & $\widehat{\Sigma}$ & 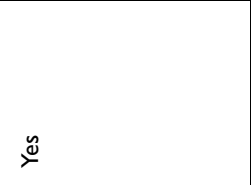 & $\stackrel{\mathscr{ٌ}}{\nearrow}$ \\
\hline 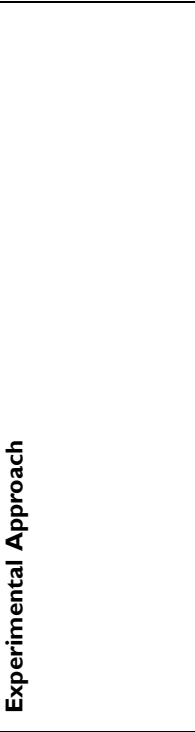 & 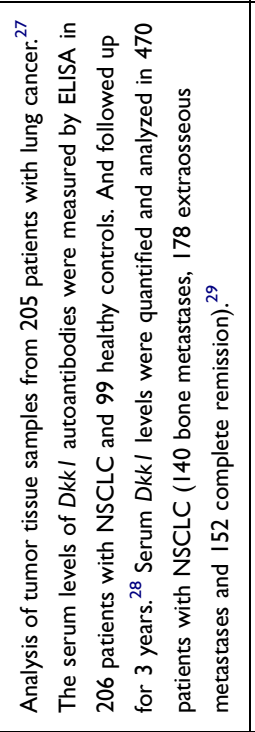 & 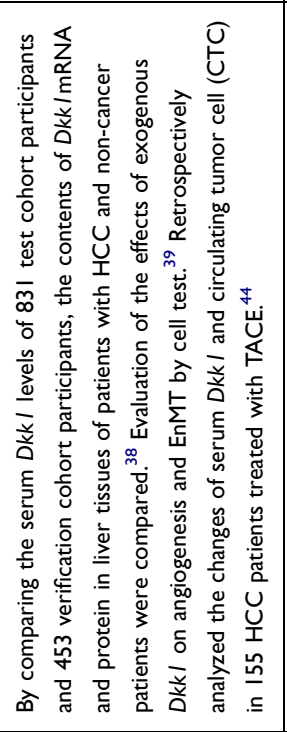 & 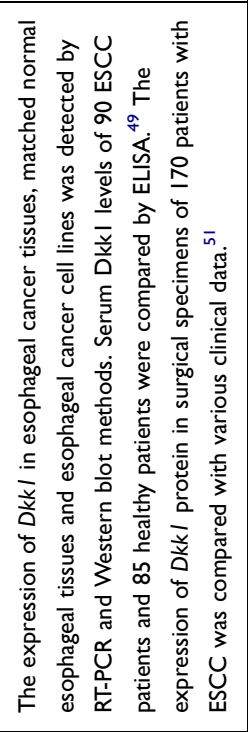 & 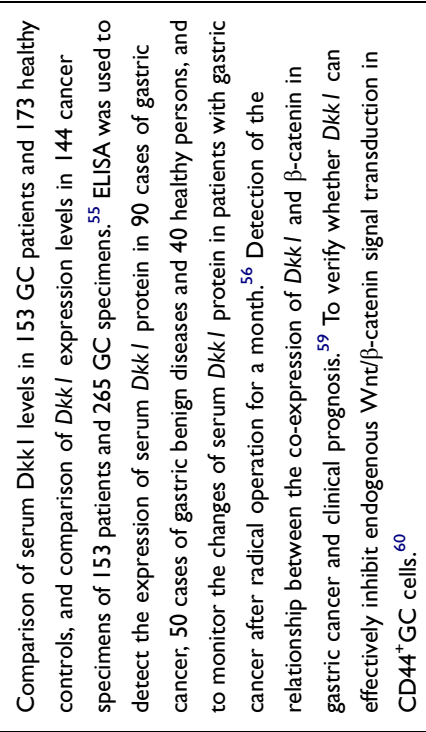 \\
\hline 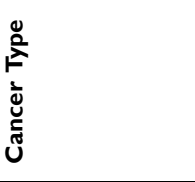 & 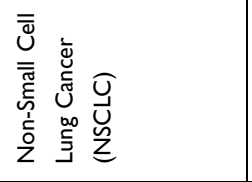 & 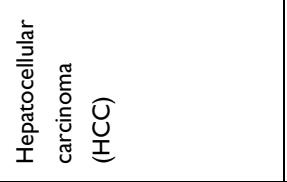 & 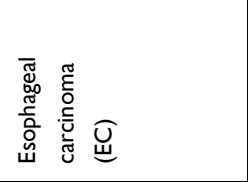 & 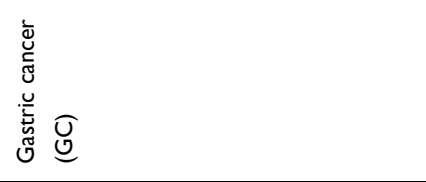 \\
\hline 㐔 & $\frac{\text { Tे }}{\frac{1}{N}}$ & $\begin{array}{l}\text { f̊ } \\
\text { d }\end{array}$ & $\begin{array}{l}\tilde{f} \\
\hat{f}\end{array}$ & $\begin{array}{l}\text { S } \\
\\
\end{array}$ \\
\hline
\end{tabular}




\begin{tabular}{|c|c|c|}
\hline 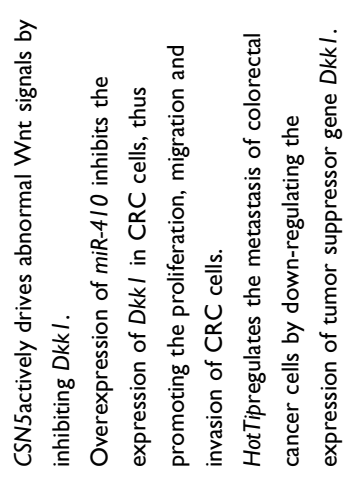 & 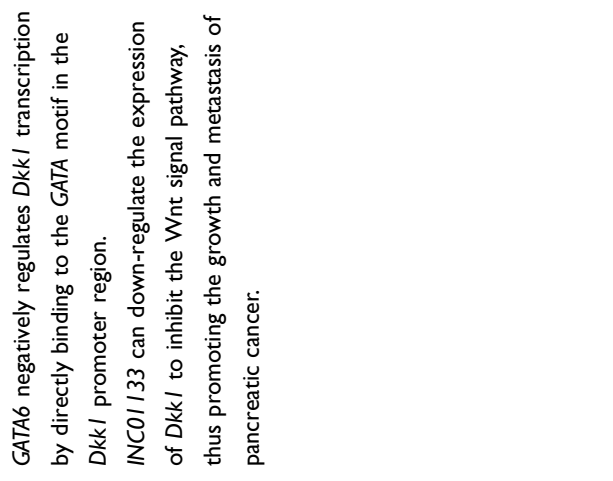 & 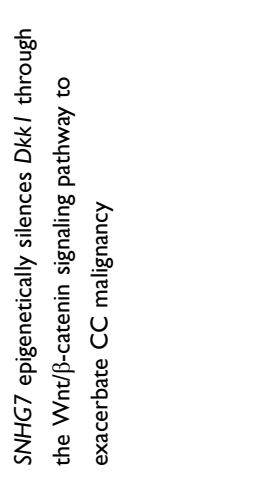 \\
\hline$\stackrel{\check{\nu}}{\nearrow}$ & $\stackrel{\check{0}}{\check{0}}$ & $\stackrel{\Xi}{\check{0}}$ \\
\hline$\check{\check{\nu}}$ & $\check{\check{D}}$ & 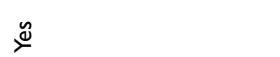 \\
\hline 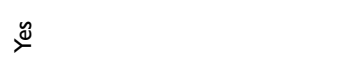 & $\stackrel{\tilde{u}}{\check{\nu}}$ & 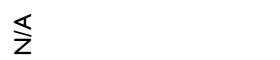 \\
\hline$\stackrel{\check{\nu}}{\check{\nu}}$ & $\stackrel{\tilde{\Xi}}{\mathscr{2}}$ & $\$$ \\
\hline 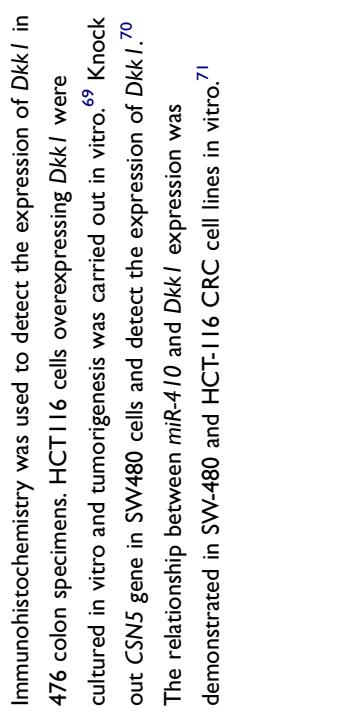 & 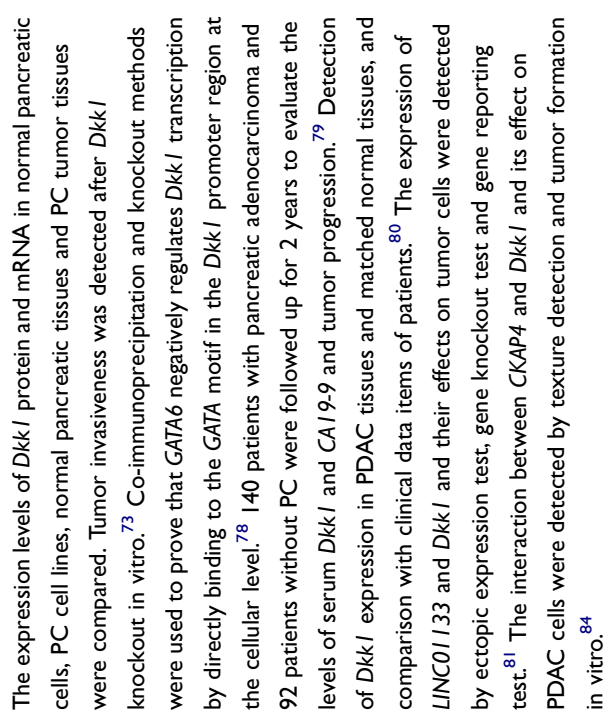 & 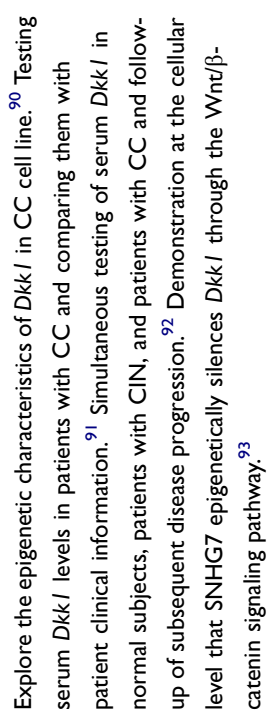 \\
\hline 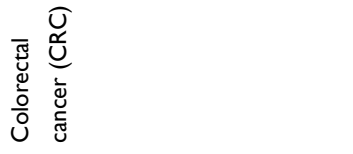 & 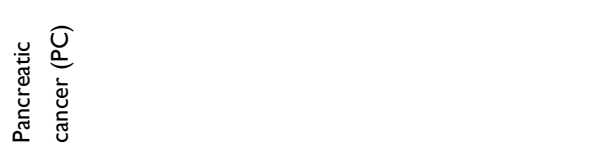 & 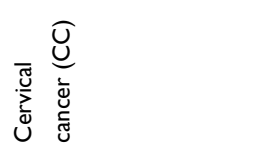 \\
\hline $\begin{array}{l}\hat{n} \\
\hat{n} \\
\underline{\omega}\end{array}$ & 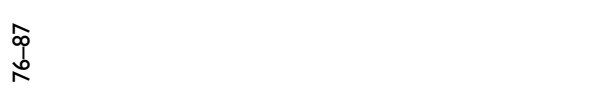 & 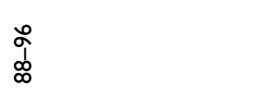 \\
\hline
\end{tabular}




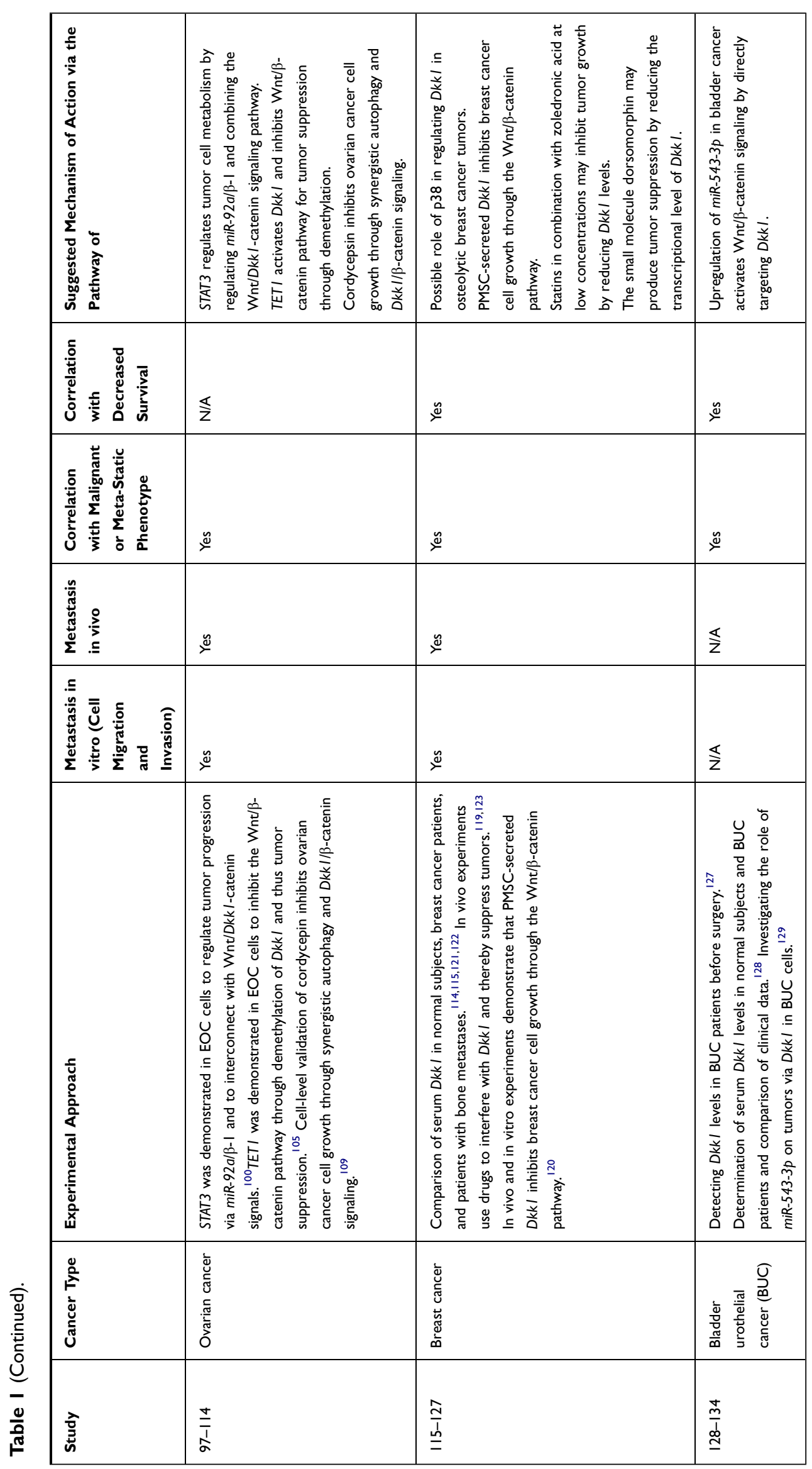




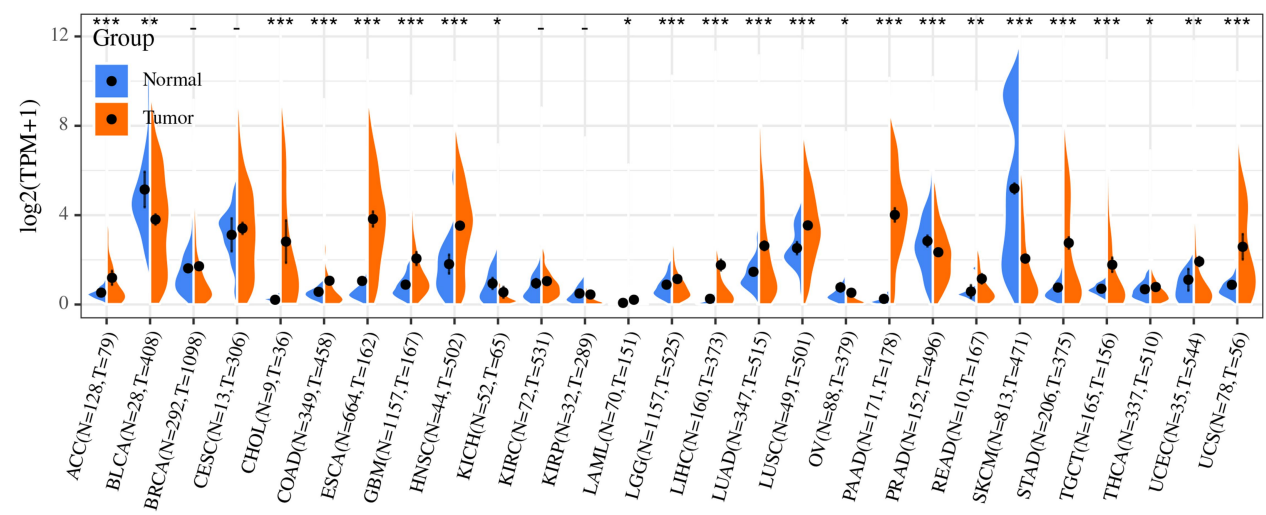

Figure 2 Analysis of differential expression of Dkkl in tumor tissues and normal tissues based on TCGA and GTEx database. Abbreviations: ACC, adrenocortical carcinoma; BLCA, bladder Urothelial Carcinoma; BRCA, breast invasive carcinoma; CESC, cervical squamous cell carcinoma and endocervical adenocarcinoma; CHOL, cholangiocarcinoma; COAD, colon adenocarcinoma; ESCA, esophageal carcinoma; GBM, glioblastoma multiforme; HNSC, head and neck squamous cell carcinoma; KICH, kidney chromophobe; KIRC, kidney renal clear cell carcinoma; KIRP, kidney renal papillary cell carcinoma; LAML, acute myeloid leukemia; LGG, brain lower grade glioma; LIHC, liver hepatocellular carcinoma; LUAD, lung adenocarcinoma; LUSC, lung squamous cell carcinoma; OV, ovarian serous cystadenocarcinoma; PAAD, pancreatic adenocarcinoma; PRAD, prostate adenocarcinoma; READ, rectum adenocarcinoma; SKCM, skin cutaneous melanoma; STAD, stomach adenocarcinoma; TGCT, testicular germ cell tumors; THCA, thyroid carcinoma; UCEC, uterine corpus endometrial carcinoma; UCS, uterine carcinosarcoma.

therapy, and blocking the activity of $D k k 1$ in mice can significantly reduce the ability of tumor invasion and metastasis in vivo. Therefore, although $D k k 1$ has two sides in tumor measurement because its mechanism is not fully elucidated, it does not affect its potential as a target for targeted therapy of tumors.

\section{Abbreviations}

AGC, advanced gastric cancer; AFP, alpha-fetoprotein; BUC, bladder urothelial cancer; CAMKII, calcium/calmodulin-dependent kinase II; Cdc42, cell division control protein 42; CSC, cancer stem cell; CSC, cancer stem cell-like cell; CC, cervical cancer; CIN, cervical epithelium to intraepithelial neoplasia; CTC, circulating tumor cell; CRC, colorectal cancer; CSN, COP9 signalosome; CKAP4, cytoskeleton associated protein 4; DAAM1, dishevelled associated activator of morphogenesis 1; Dkk1, dickkopf-1; DFS, disease-free survival; EGC, early gastric cancer; EOC, epithelial ovarian cancer; EMT, epithelial-mesenchymal transformed; EAC, esophageal adenocarcinoma; EC, esophageal cancer; ESCC, esophageal squamous cell carcinoma; SEV, extracellular vesicle; HCC, hepatocellular carcinoma; HotTip, HOXA transcript at the distal tip; HPV, human papillomavirus; HUVEC, human umbilical vein endothelial cells; IFN- $\gamma$, interferon- $\gamma$; lncRNA, longstranded non-coding RNA; MSC, mesenchymal stem cell; miRNA or miRs, MicroRNA; MAPK, mitogenactivated protein kinase; PMSCs, MSCs from the rib perichondrium; MIBC, muscle-infiltrating bladder cancer; NFAT, nuclear factor of activated T-cells; NLK, nemo-like kinase; NMIBC, non-muscle-infiltrating bladder cancer; NSCLC, non-small cell lung cancer; OS, overall survival; PC, pancreatic cancer; PDAC, pancreatic duct adenocarcinoma; RFS, relapse-free survival; $\mathrm{PKC}$, protein kinase $\mathrm{C}$; RHOA, Ras homolog gene family member A; TACE, transcatheter arterial chemoembolization; TAK-1, TGF- $\beta$ activated kinase 1; VEGFR2, vascular endothelial growth factor receptor 2; VEGF, vascular endothelial growth factor; VM,vasculogenic mimicry.

\section{Acknowledgments}

This work was supported by grants from The National Natural Science Foundation of China (81660426), The Science and Technology Project of Guizhou Province in 2017 ([2017]5803), The High-level innovative talent project of Guizhou Province in 2018 ([2018]5639), The Science and Technology Plan Project of Guiyang in 2019 ([2019]2-15), Science and Technology Plan Project of Guizhou Province in 2019 ([2019]1203).

\section{Disclosure}

The authors report no conflicts of interest in this work.

\section{References}

1. Glinka A, Wu W, Delius H, Monaghan AP, Blumenstock C, Niehrs C. Dickkopf-1 is a member of a new family of secreted proteins and functions in head induction. Nature. 1998;391:357-362. doi:10.1038/ 34848 
2. Krupnik VE, Sharp JD, Jiang C, et al. Functional and structural diversity of the human Dickkopf gene family. Gene. 1999;238:301-313. doi:10.1016/S0378-1119(99)00365-0

3. Fedi P, Bafico A, Soria AN, et al. Isolation and biochemical characterization of the human Dkk-1 homologue, a novel inhibitor of mammalian Wnt signaling. J Biol Chem. 1999;274:1946519472. doi:10.1074/jbc.274.27.19465

4. Li J, Gong W, Li X, et al. Recent progress of Wnt pathway inhibitor Dickkopf-1 in liver cancer. J Nanosci Nanotechnol. 2018;18(8):5192-5206. doi:10.1166/jnn.2018.14636

5. Logan CY, Nusse R. The Wnt signaling pathway in development and disease. Annu Rev Cell Dev Biol. 2004;20:781-810. doi:10.1146/annurev.cellbio.20.010403.113126

6. Katoh M. WNT/PCP signaling pathway and human cancer (review). Oncol Rep. 2005;14(6):1583-1588.

7. MacDonald BT, Tamai K, He X. Wnt/beta-catenin signaling: components, mechanisms, and diseases. Dev Cell. 2009;17(1):926. doi:10.1016/j.devcel.2009.06.016

8. Mao $\mathrm{B}, \mathrm{Wu} \mathrm{W}, \mathrm{Li} \mathrm{Y}$, et al. LDL-receptor-related protein 6 is a receptor for Dickkopf proteins. Nature. 2001;411(6835):321-325. doi:10.1038/35077108

9. Bafico A, Liu G, Yaniv A, Gazit A, Aaronson SA. Novel mechanism of Wnt signalling inhibition mediated by Dickkopf-1 interaction with LRP6/Arrow. Nat Cell Biol. 2001;3(7):683-686. doi: $10.1038 / 35083081$

10. Lai SL, Chien AJ, Moon RT. Wnt/Fz signaling and the cytoskeleton: potential roles in tumorigenesis. Cell Res. 2009;19:532545. doi: $10.1038 / \mathrm{cr} .2009 .41$

11. van Amerongen R, Nusse R. Towards an integrated view of Wnt signaling in development. Development. 2009;136:3205-3214. doi: $10.1242 / \mathrm{dev} .033910$

12. Abrahamsson AE, Geron I, Gotlib J, et al. Glycogen synthase kinase 3beta missplicing contributes to leukemia stem cell generation. Proc Natl Acad Sci U S A. 2009;106:3925-3929. doi:10.1073/pnas.0900189106

13. Valencia A, Román-Gómez J, Cervera J, et al. Wnt signaling pathway is epigenetically regulated by methylation of Wnt antagonists in acute myeloid leukemia. Leukemia. 2009;23:1658-1666. doi:10.1038/leu.2009.86

14. Roman-Gomez J, Cordeu L, Agirre X, et al. Epigenetic regulation of Wnt-signaling pathway in acute lymphoblastic leukemia. Blood. 2007;109:3462-3469. doi:10.1182/blood-2006-09047043

15. Cancer Genome Atlas Network. Comprehensive molecular characterization of human colon and rectal cancer. Nature. 2012;487:330-337. doi:10.1038/nature11252

16. Qin WX, Zhang HT, Yu YJ, et al. Uses of DKK-1 protein in diagnosis of cancer. Patent, WO/2007/104181 A1. 2007.

17. Yu YJ, Wan XZ, Yu B, et al. Expression of Dickkopf (Dkk1) in liver cancer and in multiple human cancer cell lines. Zhongliu. 2006;26:1109-1112.

18. Yu B, Yang X, Xu Y, et al. Elevated expression of Dkk1 is associated with cytoplasmic/nuclear $\beta$-catenin accumulation and poor prognosis in hepatocellular carcinomas. $J$ Hepatol. 2009;50:948-957. doi:10.1016/j.jhep.2008.11.020

19. Sato N, Yamabuki T, Takano A, et al. Wnt inhibitor Dickkopf-1 as a target for passive cancer immunotherapy. Cancer Res. 2010;70:5326-5336. doi:10.1158/0008-5472.CAN-09-3879

20. Tung EK, Mak CK, Fatima S, et al. Clinicopathological and prognostic significance of serum and tissue Dickkopf-1 levels in human hepatocellular carcinoma. Liver Int. 2011;31:1494-1504. doi:10.1111/j.1478-3231.2011.02597.x

21. Maniotis AJ, Folberg R, Hess A, et al. Vascular channel formation by human melanoma cells in vivo and in vitro: vasculogenic mimicry. Am J Pathol. 1999;155:739-752. doi:10.1016/S00029440(10)65173-5
22. Sun T, Zhao N, Zhao XL, et al. Expression and functional significance of Twist1 in hepatocellular carcinoma: its role in vasculogenic mimicry. Hepatology. 2010;51:545-556. doi:10.1002/ hep. 23311

23. Zhang D, Sun B, Zhao X, et al. Twist1 expression induced by sunitinib accelerates tumor cell vasculogenic mimicry by increasing the population of CD133+ cells in triple-negative breast cancer. Mol Cancer. 2014;13:207. doi:10.1186/14764598-13-207

24. Schnegg CI, Yang MH, Ghosh SK, et al. Induction of vasculogenic mimicry overrides VEGF-A silencing and enriches stemlike cancer cells in melanoma. Cancer Res. 2015;75:1682-1690. doi:10.1158/0008-5472.CAN-14-1855

25. Yang DH, Yoon JY, Lee SH, et al. Wnt5a is required for endothelial differentiation of embryonic stem cells and vascularization via pathways involving both Wnt/beta-catenin and protein kinase Calpha. Circ Res. 2009;104:372-379. doi:10.1161/ CIRCRESAHA.108.185405

26. Qi L, Sun B, Liu Z, et al. Dickkopf-1 inhibits epithelial-mesenchymal transition of colon cancer cells and contributes to colon cancer suppression. Cancer Sci. 2012;103:828-835. doi:10.1111/ j.1349-7006.2012.02222.x

27. Yao L, Zhang D, Zhao X, et al. Dickkopf-1-promoted vasculogenic mimicry in non-small cell lung cancer is associated with EMT and development of a cancer stem-like cell phenotype. $J$ Cell Mol Med. 2016;20(9):1673-1685. doi:10.1111/jcmm.12862

28. Shen L, Wu X, Tan J, et al. Combined detection of dickkopf-1 subtype classification autoantibodies as biomarkers for the diagnosis and prognosis of non-small cell lung cancer. Onco Targets Ther. 2017;10:3545-3556. doi:10.2147/OTT.S134162

29. Qiao R, Zhong R, Chang Q, et al. Serum dickkopf-1 as a clinical and prognostic factor in non-small cell lung cancer patients with bone metastases. Oncotarget. 2017;8(45):79469-79479. doi:10.18632/oncotarget.18446

30. Abdelaziz AO, Elbaz TM, Shousha HI, et al. Survival and prognostic factors for hepatocellular carcinoma: an Egyptian multidisciplinary clinic experience. Asian Pac J Cancer Prev. 2014;15:3915-3920. doi:10.7314/APJCP.2014.15.9.3915

31. Omata M, Cheng AL, Kokudo N, et al. Asia-Pacific clinical practice guidelines on the management of hepatocellular carcinoma: a 2017 update. Hepatol Int. 2017;11:317-370.

32. Siegel RL, Miller KD, Jemal A. Cancer statistics, 2017. $C A$ Cancer J Clin. 2017;67:7-30. doi:10.3322/caac.21387

33. Sangiovanni A, Colombo M. Treatment of hepatocellular carcinoma: beyond international guidelines. Liver Int. 2016;36(Supp1 1):124-129. doi:10.1111/liv.13028

34. Aghoram R, Cai P, Dickinson JA. Alpha-foetoprotein and/or liver ultrasonography for screening of hepatocellular carcinoma in patients with chronic hepatitis B. Cochrane Database Syst Rev. 2012;9:Cd002799.

35. Llovet JM, Ducreux M, Lencioni R, et al. European association for the study of the liver, european organization for research and treatment of cancer, EASL-EORTC clinical practice guidelines: management of hepatocellular carcinoma. $J$ Hepatol. 2012;56:908-943.

36. Bruix J, Sherman M. Management of hepatocellular carcinoma: an update. Hepatology. 2011;53:1020-1022. doi:10.1002/ hep.24199

37. Marrero JA, Feng Z, Wang Y, et al. Alpha-fetoprotein, desgamma carboxyprothrombin, and lectin-bound alpha-fetoprotein in early hepatocellular carcinoma. Gastroenterology. 2009;137:110-118. doi:10.1053/j.gastro.2009.04.005

38. Shen Q, Fan J, Yang XR, et al. Serum DKK1 as a protein biomarker for the diagnosis of hepatocellular carcinoma: a large-scale, multicentre study. Lancet Oncol. 2012;13(8):817826. doi:10.1016/S1470-2045(12)70233-4 
39. Mazon M, Masi D, Carreau M. Modulating Dickkopf-1: a strategy to monitor or treat cancer? Cancers (Basel). 2016;8:62.

40. Choi SH, Kim H, Lee HG, et al. Dickkopf-1 induces angiogenesis via VEGF receptor 2 regulation independent of the Wnt signaling pathway. Oncotarget. 2017;8(35):58974-58984. doi:10.18632/ oncotarget.19769

41. El-Serag HB, Marrero JA, Rudolph L, et al. Diagnosis and treatment of hepatocellular carcinoma. Gastroenterology. 2008;134:1752-1763. doi:10.1053/j.gastro.2008.02.090

42. Lo CM, Ngan H, Tso WK, et al. Randomized controlled trial of transarterial lipiodol chemoembolization for unresectable hepatocellular carcinoma. Hepatology. 2002;35:1164-1171. doi:10.1053/ jhep. 2002.33156

43. Raoul JL, Sangro B, Forner A, et al. Evolving strategies for the management of intermediate-stage hepatocellular carcinoma: available evidence and expert opinion on the use of transarterial chemoembolization. Cancer Treat Rev. 2011;37:212-220. doi:10.1016/j.ctrv.2010.07.006

44. Wu X, Yang C, Yu H, Cao F, Shan Y, Zhao W. The predictive values of serum dickkopf-1 and circulating tumor cells in evaluating the efficacy of transcatheter arterial chemoembolization treatment on hepatocellular carcinoma. Medicine (Baltimore). 2019;98(30):e16579. doi:10.1097/MD.0000000000016579

45. Zhang HF, Wu C, Alshareef A, et al. The PI3K/AKT/c-MYC axis promotes the acquisition of cancer stem-like features in esophageal squamous cell carcinoma. Stem Cells. 2016;34:2040-2051. doi:10.1002/stem.2395

46. Agrawal N, Jiao Y, Bettegowda C, et al. Comparative genomic analysis of esophageal adenocarcinoma and squamous cell carcinoma. Cancer Discov. 2012;2:899-905. doi:10.1158/2159-8290.CD-120189

47. Liang Y, Liu JL, Wu Y, Zhang ZY, Wu R. Cyclooxygenase-2 polymorphisms and susceptibility to esophageal cancer: a meta-analysis. Tohoku J Exp Med. 2011;223:137-144. doi:10.1620/tjem.223.137

48. Jemal A, Bray F, Center MM, Ferlay J, Ward E, Forman D. Global cancer statistics. CA Cancer J Clin. 2011;61:69. doi:10.3322/caac. 20107

49. Li S, Qin X, Liu B, et al. Dickkopf-1 is involved in invasive growth of esophageal cancer cells. J Mol Histol. 2011;42(6):491498. doi:10.1007/s10735-011-9347-1

50. Begenik H, Kemik AS, Emre H, et al. The association between serum Dickkopf-1 levels and esophageal squamous cell carcinoma. Hum Exp Toxicol. 2014;33(8):785-788. doi:10.1177/ 0960327113510537

51. Makino T, Yamasaki M, Takemasa I, et al. Dickkopf-1 expression as a marker for predicting clinical outcome in esophageal squamous cell carcinoma. Ann Surg Oncol. 2009;16(7):2058-2064. doi:10.1245/s10434-009-0476-7

52. Ferlay J, Soerjomataram I, Dikshit R, et al. Cancer incidence and mortality worldwide: sources, methods and major patterns in GLOBOCAN 2012. Int $J$ Cancer. 2015;136(5):E359-E386. doi:10.1002/ijc. 29210

53. Yada T, Yokoi C, Uemura N. The current state of diagnosis and treatment for early gastric cancer. Diagn Ther Endosc. 2013;2013:241320. doi:10.1155/2013/241320

54. Wagner AD, Grothe W, Haerting J, Kleber G, Grothey A, Fleig WE. Chemotherapy in advanced gastric cancer: a systematic review and meta-analysis based on aggregate data. $J$ Clin Oncol. 2006;24(18):2903-2909. doi:10.1200/JCO.2005.05.0245

55. Lee HS, Lee HE, Park DJ, Kim HH, Kim WH, Park KU. Clinical significance of serum and tissue Dickkopf- 1 levels in patients with gastric cancer. Clin Chim Acta. 2012;413(21-22):17531760. doi:10.1016/j.cca.2012.07.003

56. Zhuang GF, Tan Y, Zeng JT, et al. Expression of serum Dickkopf1 in gastric cancer patients. Asian Pac J Trop Med. 2015;8 (10):870-872. doi:10.1016/j.apjtm.2015.09.016
57. Liu QR, Li YF, Deng ZQ, Cao JQ. Prognostic significance of Dickkopf-1 in gastric cancer survival: a meta-analysis. Genet Test Mol Biomarkers. 2016;20(4):170-175. doi:10.1089/ gtmb.2015.0154

58. Zhan $\mathrm{T}$, Rindtorff $\mathrm{N}$, Boutros $\mathrm{M}$. Wnt signaling in cancer. Oncogene. 2017;36(11):1461-1473.

59. Hong SA, Yoo SH, Lee HH, et al. Prognostic value of Dickkopf-1 and $\beta$-catenin expression in advanced gastric cancer. $B M C$ Cancer. 2018;18(1):506. doi:10.1186/s12885-018-4420-8

60. Wang B, Liu J, Ma LN, et al. Chimeric $5 / 35$ adenovirus-mediated Dickkopf-1 overexpression suppressed tumorigenicity of $\mathrm{CD} 44^{+}$ gastric cancer cells via attenuating Wnt signaling. $J$ Gastroenterol. 2013;48(7):798-808. doi:10.1007/s00535-0120711-z

61. Ferrarelli LK. Treating WNT-driven colorectal cancer. Science. 2017;356(6345):1346-1348. doi:10.1126/science.356.6345.1346-

62. Chen W, Zheng R, Zeng H, Zhang S, He J. Annual report on status of cancer in China, 2011. Chin J Cancer Res. 2015;27:212. doi:10.1186/s40880-015-0001-2

63. Galamb O, Kalmar A, Peterfia B, et al. Aberrant DNA methylation of WNT pathway genes in the development and progression of CIMP-negative colorectal cancer. Epigenetics. 2016;11 (8):588-602. doi:10.1080/15592294.2016.1190894

64. Rennoll S, Yochum G. Regulation of MYC gene expression by aberrant Wnt/beta-catenin signaling in colorectal cancer. World $J$ Biol Chem. 2015;6(4):290-300. doi:10.4331/wjbc.v6.i4.290

65. Siegel RL, Miller KD, Fedewa SA, et al. Colorectal cancer statistics, 2017. CA Cancer J Clin. 2017;67:177-193.

66. Fan C, Lin Y, Mao Y, et al. MicroRNA-543 suppresses colorectal cancer growth and metastasis by targeting KRAS, MTA1 and HMGA2. Oncotarget. 2016;7:21825-21839. doi:10.18632/ oncotarget.7989

67. Aguilera O, Fraga MF, Ballestar E, et al. Epigenetic inactivation of the Wnt antagonist DICKKOPF-1 (DKK-1) gene in human colorectal cancer. Oncogene. 2006;25(29):4116-4121. doi:10.1038/sj.onc. 1209439

68. Rawson JB, Manno M, Mrkonjic M, et al. Promoter methylation of Wnt antagonists DKK1 and SFRP1 is associated with opposing tumor subtypes in two large populations of colorectal cancer patients. Carcinogenesis. 2011;32(5):741-747. doi:10.1093/carcin/bgr020

69. Liu Z, Sun B, Qi L, et al. Dickkopf-1 expression is down-regulated during the colorectal adenoma-carcinoma sequence and correlates with reduced microvessel density and VEGF expression. Histopathology. 2015;67(2):158-166. doi:10.1111/his.12474

70. Jumpertz S, Hennes T, Asare Y, Schütz AK, Bernhagen J. CSN5/ JAB1 suppresses the WNT inhibitor DKK1 in colorectal cancer cells. Cell Signal. 2017;34:38-46. doi:10.1016/j. cellsig.2017.02.013

71. Wang W, He Y, Rui J, Xu MQ. miR-410 acts as an oncogene in colorectal cancer cells by targeting dickkopf-related protein 1 via the Wnt/ $\beta$-catenin signaling pathway. Oncol Lett. 2019;17 (1):807-814.

72. Rui Y, Hu M, Wang P, et al. LncRNA HOTTIP mediated DKK1 downregulation confers metastasis and invasion in colorectal cancer cells. Histol Histopathol. 2019;34(6):619-630.

73. Siegel RL, Miller KD, Jemal A. Cancer statistics, 2016. $C A$ Cancer J Clin. 2016;66(1):7-30. doi:10.3322/caac.21332

74. Stotz M, Eisner F, Szkandera J, et al. Clinico-pathological characteristics and clinical outcome of different histological types of pancreatic cancer in a large Middle European series. J Clin Pathol. 2013;66(9):753-757. doi:10.1136/jclinpath-2012-201394

75. Klein AP. Identifying people at a high risk of developing pancreatic cancer. Nat Rev Cancer. 2013;13(1):66-74. doi:10.1038/ $\operatorname{nrc} 3420$ 
76. Hidalgo M. Pancreatic cancer. $N$ Engl J Med. 2010;362 (17):1605-1617. doi:10.1056/NEJMra0901557

77. Takahashi N, Fukushima T, Yorita K, Tanaka H, Chijiiwa K, Kataoka H. Dickkopf-1 is overexpressed in human pancreatic ductal adenocarcinoma cells and is involved in invasive growth. Int $J$ Cancer. 2010;126(7):1611-1620.

78. Zhong Y, Wang Z, Fu B, et al. GATA6 activates Wnt signaling in pancreatic cancer by negatively regulating the Wnt antagonist Dickkopf-1. PLoS One. 2011;6(7):e22129.

79. Han SX, Zhou X, Sui X, et al. Serum dickkopf-1 is a novel serological biomarker for the diagnosis and prognosis of pancreatic cancer. Oncotarget. 2015;6(23):19907-19917. doi:10.18632/ oncotarget.4529

80. Liu DJ, Xie YX, Liu XX, et al. The role of Dickkopf-1 as a potential prognostic marker in pancreatic ductal adenocarcinoma. Cell Cycle. 2017;16(17):1622-1629. doi:10.1080/ 15384101.2017 .1356510

81. Tang Y, Zhang Z, Tang Y, Chen X, Zhou J. Identification of potential target genes in pancreatic ductal adenocarcinoma by bioinformatics analysis. Oncol Lett. 2018;16(2):2453-2461.

82. Pang EJ, Yang R, Fu XB, Liu YF. Overexpression of long noncoding RNA MALAT1 is correlated with clinical progression and unfavorable prognosis in pancreatic cancer. Tumour Biol. 2015;36 (4):2403-2407. doi:10.1007/s13277-014-2850-8

83. Weng YC, Ma J, Zhang J, Wang JC. Long non-coding RNA LINC01133 silencing exerts antioncogenic effect in pancreatic cancer through the methylation of DKK1 promoter and the activation of Wnt signaling pathway. Cancer Biol Ther. 2019;20 (3):368-380. doi:10.1080/15384047.2018.1529110

84. Kimura H, Yamamoto H, Harada T, et al. CKAP4, a DKK1 receptor, is a biomarker in exosomes derived from pancreatic cancer and a molecular target for therapy. Clin Cancer Res. 2019;25(6):1936-1947. doi:10.1158/1078-0432.CCR-18-2124

85. Bray F, Ferlay J, Soerjomataram I, Siegel RL, Torre LA, Jemal A. Global cancer statistics 2018: GLOBOCAN estimates of incidence and mortality worldwide for 36 cancers in 185 countries. CA Cancer J Clin. 2018;68(6):394-424. doi:10.3322/caac.21492

86. Small W, Bacon MA, Bajaj A, et al. Cervical cancer: a global health crisis. Cancer. 2017;123(13):2404-2412. doi:10.1002/ cncr.30667

87. Kessler TA. Cervical cancer: prevention and early detection. Semin Oncol Nurs. 2017;33(2):172-183. doi:10.1016/j. soncn.2017.02.005

88. Berman TA, Schiller JT. Human papillomavirus in cervical cancer and oropharyngeal cancer: one cause, two diseases. Cancer. 2017;123(12):2219-2229.

89. Analytical BS, Barretos CH, Cancer Genome Atlas Research Network. Integrated genomic and molecular characterization of cervical cancer. Nature. 2017;543(7645):378-384.

90. Lee J, Yoon YS, Chung JH. Epigenetic silencing of the WNT antagonist DICKKOPF-1 in cervical cancer cell lines. Gynecol Oncol. 2008;109(2):270-274. doi:10.1016/j.ygyno.2008.01.034

91. Jiang T, Wang S, Huang L, Zhang S. Clinical significance of serum DKK-1 in patients with gynecological cancer. Int $J$ Gynecol Cancer. 2009;19(7):1177-1181. doi:10.1111/ IGC.0b013e31819d8b2d

92. Jiang T, Huang L, Zhang S. DKK-1 in serum as a clinical and prognostic factor in patients with cervical cancer. Int $J$ Biol Markers. 2013;28(2):221-225. doi:10.5301/jbm.5000005

93. Chi C, Li M, Hou W, Chen Y, Zhang Y, Chen J. Long noncoding RNA SNHG7 activates Wnt/ $\beta$-catenin signaling pathway in cervical cancer cells by epigenetically silencing DKK1. Cancer Biother Radiopharm. 2020. doi:10.1089/ cbr.2019.3004

94. Siegel RL, Miller KD, Jemal A. Cancer statistics, 2018. CA Cancer J Clin. 2018;68(1):7-30. doi:10.3322/caac.21442
95. Torre LA, Bray F, Siegel RL, Ferlay J, Lortet-Tieulent J, Jemal A. Global cancer statistics, 2012. CA Cancer J Clin. 2015;65(2):87108. doi:10.3322/caac. 21262

96. Li X, Tang M, Zhu Q, Wang X, Lin Y, Wang X. The exosomal integrin $\alpha 5 \beta 1$ /AEP complex derived from epithelial ovarian cancer cells promotes peritoneal metastasis through regulating mesothelial cell proliferation and migration. Cell Oncol (Dordr). 2020;43(2):263-277.

97. Vaughan S, Coward JI, Bast RC, et al. Rethinking ovarian cancer: recommendations for improving outcomes. Nat Rev Cancer. 2011;11(10):719-725. doi:10.1038/nrc3144

98. Garrido MP, Bruneau N, Vega M, Selman A, Tapia JC, Romero C. Follicle-stimulating hormone promotes nerve growth factor and vascular endothelial growth factor expression in epithelial ovarian cells. Histol Histopathol. 2020;18226.

99. Barbolina MV, Liu Y, Gurler H, et al. Matrix rigidity activates Wnt signaling through down-regulation of Dickkopf-1 protein. $J$ Biol Chem. 2013;288(1):141-151. doi:10.1074/jbc.M112.431411

100. Chen MW, Yang ST, Chien MH, et al. The STAT3-miRNA-92Wnt signaling pathway regulates spheroid formation and malignant progression in ovarian cancer. Cancer Res. 2017;77(8):19551967. doi:10.1158/0008-5472.CAN-16-1115

101. Kohli RM, Zhang Y. TET enzymes, TDG and the dynamics of DNA demethylation. Nature. 2013;502(7472):472-479. doi:10.1038/nature12750

102. Scourzic L, Mouly E, Bernard OA. TET proteins and the control of cytosine demethylation in cancer. Genome Med. 2015;7(1):9.

103. Kraus TF, Greiner A, Steinmaurer M, Dietinger V, Guibourt V, Kretzschmar HA. Genetic characterization of ten-eleven-translocation methylcytosine dioxygenase alterations in human glioma. $J$ Cancer. 2015;6(9):832-842. doi:10.7150/jca.12010

104. Rawłuszko-Wieczorek AA, Siera A, Horbacka K, Horst N, Krokowicz P, Jagodziński PP. Clinical significance of DNA methylation mRNA levels of TET family members in colorectal cancer. J Cancer Res Clin Oncol. 2015;141(8):1379-1392. doi:10.1007/s00432-014-1901-2

105. Duan H, Yan Z, Chen W, et al. TET1 inhibits EMT of ovarian cancer cells through activating $\mathrm{Wnt} / \beta$-catenin signaling inhibitors DKK1 and SFRP2. Gynecol Oncol. 2017;147(2):408-417. doi:10.1016/j.ygyno.2017.08.010

106. Chang W, Lim S, Song H, et al. Cordycepin inhibits vascular smooth muscle cell proliferation. Eur J Pharmacol. 2008;597(13):64-69. doi:10.1016/j.ejphar.2008.08.030

107. Nakamura K, Yoshikawa N, Yamaguchi Y, Kagota S, Shinozuka K, Kunitomo M. Antitumor effect of cordycepin (3'-deoxyadenosine) on mouse melanoma and lung carcinoma cells involves adenosine A3 receptor stimulation. Anticancer Res. 2006;26(1A):43-47.

108. Shi P, Huang Z, Tan X, Chen G. Proteomic detection of changes in protein expression induced by cordycepin in human hepatocellular carcinoma BEL-7402 cells. Methods Find Exp Clin Pharmacol. 2008;30(5):347-353. doi:10.1358/mf.2008.30.5.1186085

109. Jang HJ, Yang KE, Hwang IH, et al. Cordycepin inhibits human ovarian cancer by inducing autophagy and apoptosis through Dickkopf-related protein $1 / \beta$-catenin signaling. Am J Transl Res. 2019;11(11):6890-6906.

110. Betella I, Turbitt WJ, Szul T, et al. Wnt signaling modulator DKK1 as an immunotherapeutic target in ovarian cancer. Gynecol Oncol. 2020.

111. Saad ED, Katz A, Buyse M. Overall survival and post-progression survival in advanced breast cancer: a review of recent randomized clinical trials. J Clin Oncol. 2010;28(11):1958-1962. doi:10.1200/JCO.2009.25.5414

112. Gotay CC, Kawamoto CT, Bottomley A, Efficace F. The prognostic significance of patient-reported outcomes in cancer clinical trials. J Clin Oncol. 2008;26(8):1355-1363. doi:10.1200/ JCO.2007.13.3439 
113. Karaman S, Detmar M. Mechanisms of lymphatic metastasis. $J$ Clin Invest. 2014;124(3):922-928. doi:10.1172/JCI71606

114. Voorzanger-Rousselot N, Journe F, Doriath V, Body JJ, Garnero P. Assessment of circulating Dickkopf-1 with a new two-site immunoassay in healthy subjects and women with breast cancer and bone metastases. Calcif Tissue Int. 2009;84(5):348-354. doi:10.1007/s00223-009-9225-y

115. Xu WH, Liu ZB, Yang C, Qin W, Shao ZM. Expression of dickkopf-1 and beta-catenin related to the prognosis of breast cancer patients with triple negative phenotype. PLoS One. 2012;7(5):e37624. doi:10.1371/journal.pone.0037624

116. Mariz K, Ingolf JB, Daniel H, Teresa NJ, Erich-Franz S. The Wnt inhibitor dickkopf-1: a link between breast cancer and bone metastases. Clin Exp Metastasis. 2015;32(8):857-866. doi:10.1007/s10585-015-9750-1

117. Rachner TD, Göbel A, Browne A, Hötzel J, Rauner M, Hofbauer LC. P38 regulates the Wnt inhibitor Dickkopf-1 in breast cancer. Biochem Biophys Res Commun. 2015;466(4):728-732. doi:10.1016/j.bbrc.2015.09.101

118. Rachner TD, Göbel A, Thiele S, et al. Dickkopf-1 is regulated by the mevalonate pathway in breast cancer. Breast Cancer Res. 2014;16(1):R20.

119. Göbel A, Browne AJ, Thiele S, Rauner M, Hofbauer LC, Rachner TD. Potentiated suppression of Dickkopf-1 in breast cancer by combined administration of the mevalonate pathway inhibitors zoledronic acid and statins. Breast Cancer Res Treat. 2015;154 (3):623-631. doi:10.1007/s10549-015-3624-8

120. Li M, Cai H, Yang Y, et al. Perichondrium mesenchymal stem cells inhibit the growth of breast cancer cells via the DKK-1/Wnt $\beta$-catenin signaling pathway. Oncol Rep. 2016;36(2):936-944.

121. Liu JT, Guo WB, Sun JY. Serum Dickkopf-1 acts as a new biomarker in human breast cancer. Minerva Med. 2017;108(4):334-340.
122. Kasoha M, Bohle RM, Seibold A, Gerlinger C, Juhasz-Böss I, Solomayer EF. Dickkopf-1 (Dkk1) protein expression in breast cancer with special reference to bone metastases. Clin Exp Metastasis. 2018;35(8):763-775. doi:10.1007/s10585-018-9937-3

123. Jaschke N, Kleymann A, Hofbauer LC, Göbel A, Rachner TD. Dorsomorphin: a novel inhibitor of Dickkopf-1 in breast cancer. Biochem Biophys Res Commun. 2020;524(2):360-365. doi:10.1016/j.bbrc.2020.01.106

124. Li K, Lin T, Xue W, et al.. Current status of diagnosis and treatment of bladder cancer in China - analyses of Chinese Bladder Cancer Consortium database. Asian J Urol. 2015;2(2):63-69.

125. Alfred Witjes J, Lebret T, Compérat EM, et al. Updated 2016 EAU guidelines on muscle-invasive and metastatic bladder cancer. Eur Urol. 2017;71(3):462-475. doi:10.1016/j.eururo.2016.06.020

126. Knowles MA, Hurst CD. Molecular biology of bladder cancer: new insights into pathogenesis and clinical diversity. Nat Rev Cancer. 2015;15(1):25-41. doi:10.1038/nrc3817

127. Kaba M, Pirincci N, Benli E, et al. Dickkopf-1 levels in Turkish patients with bladder cancer and its association with clinicopathological features. Asian Pac J Cancer Prev. 2014;15(1):381-384. doi:10.7314/APJCP.2014.15.1.381

128. Sun DK, Wang L, Wang JM, Zhang P. Serum Dickkopf-1 levels as a clinical and prognostic factor in patients with bladder cancer. Genet Mol Res. 2015;14(4):18181-18187. doi:10.4238/2015. December.23.5

129. Gao RL, Chen XR, Li YN, et al. Upregulation of miR-543-3p promotes growth and stem cell-like phenotype in bladder cancer by activating the Wnt/ $\beta$-catenin signaling pathway. Int J Clin Exp Pathol. 2017;10(9):9418-9426.

130. Kagey MH, He X. Rationale for targeting the Wnt signalling modulator Dickkopf-1 for oncology. Br J Pharmacol. 2017;174 (24):4637-4650. doi:10.1111/bph.13894

\section{Publish your work in this journal}

Cancer Management and Research is an international, peer-reviewed open access journal focusing on cancer research and the optimal use of preventative and integrated treatment interventions to achieve improved outcomes, enhanced survival and quality of life for the cancer patient.
The manuscript management system is completely online and includes a very quick and fair peer-review system, which is all easy to use. Visit http://www.dovepress.com/testimonials.php to read real quotes from published authors. 